DOI: 10.4274/jarem.galenos.2021.3794

J Acad Res Med 2021;11(1):24-31

\title{
Psychiatric Comorbidity, Length of Hospital Stays and Readmission Rates in Opiate Addicts Treated in Inpatient Service
}

\author{
Bahadır Geniş1, (1) Behçet Coşar2, (1) Zehra Arıkan² \\ ${ }^{1}$ Kocaeli University Faculty of Medicine, Department of Psychiatry, Kocaeli, Turkey \\ ${ }^{2}$ Gazi University Faculty of Medicine, Department of Psychiatry, Ankara, Turkey
}

Cite this article as: Geniş B, Coşar B, Arıkan Z. Psychiatric Comorbidity, Length of Hospital Stays and Readmission Rates in Opiate Addicts Treated in Inpatient Service. J Acad Res Med 2021;11(1):24-31

\begin{abstract}
Objective: In this study, it was aimed to investigate psychiatric comorbidity, long hospitalization reasons and readmission reasons of opiate addicts treated in inpatient service.

Methods: The study data consisted of patient records treated at Gazi University Hospital Alcohol and Drug Addiction Clinic between 1 January 2005 and 31 December 2017. Four hundred eighty four people with primary diagnosis of opiate addiction were included in the analysis. One hundred of these patients had recurrent hospitalizations.

Results: While the average age of the sample was $29.74 \pm 7.05,89.9 \%(n=435)$ were male. The presence of depression as a comorbidity in opiate addiction increased the length of hospitalization 3.3 times [odds ratio (OR): 3.362] and the psychotic symptom 5.4 times (OR: 5.417). In addition to opiate addiction, the diagnosis of anxiety disorder increased the risk of readmission 3.3 times (OR: 3.321), while the diagnosis of personality disorder reduced the risk of readmission 4.58 times (OR: 0.218$)$. It was observed that $5 \%(n=5)$ of the patients were re-admitted within the first month and $29 \%$ $(n=29)$ within the first three months.

Conclusion: One of every three opiate addicts is admitted in the first three months after discharge. Having anxiety disorder increases recurrent hospitalization 3.3 times, while having personality disorder decreases 4.5 times. Further studies should be conducted on whether short hospitalization periods increase readmission rates.
\end{abstract}

Keywords: Opiate addiction, length of stay, patient readmission, comorbidity, depression

\section{INTRODUCTION}

Opiate addiction is a serious, chronic and recurrent psychiatric disease (1). In the drug report published by the World Health Organization (WHO) in 2018, it was stated that there were 275 million drug users, 34 million of which were opiate users (2). Although opiate use constitutes a relatively small part of all drug use, it accounts for $76 \%$ of drug-induced deaths (2). As a result of opiate-containing drug use in 2015, 167,750 people lost their lives (2). Drug use in Turkey is less common than the world average. However, the increase in use over the past years shows that drug addictions are gradually increasing. The Turkey drug report published in 2019 showed that the first drug to be tried is cannabis, and the second is heroin (3). All these data show that drug treatment and health services continue to be inadequate and drug addictions are still a serious public health problem.

ORCID IDs of the authors: B.G. 0000-0001-8541-7670; B.C. 0000-0002-6422-499X; Z.A. 0000-0003-3138-2315.

Corresponding Author/Sorumlu Yazar: Bahadır Geniş, E-mail: bahadirgenis06@gmail.com
Received Date/Geliş Tarihi: 02.10.2020 Accepted Date/Kabul Tarihi: 04.01 .2021

CC Copyright 2021 by University of Health Sciences Turkey, Gaziosmanpaşa Training and Research Hospital. Available on-line at www.jarem.org 
Illegal use of opiates has significant social burden such as frequent reference to emergency services, overdose use, deterioration of family relationships, the increase in violence, criminal activity, work loss, increase in general medical illnesses and adverse effect on the course of psychiatric illnesses (4). In addition to these burdens, patients apply to clinics for treatments often due to the high recurrence rates. Addiction treatment includes a communityoriented treatment and rehabilitation treatment that includes psychosocial variables as well as pharmacological approaches (5). Although these treatments are improved day by day, relapse is still quite common. Even in opiate addicted patients receiving agonist maintenance treatment, it is reported that more than $50 \%$ of the treatment discontinues in the first three weeks of treatment (6).

There are many difficulties in addictions, such as the recurrent and chronic nature of the disease, the presence of accompanying psychiatric diseases and the high rate of treatment non-compliance in patients. These difficulties affect the treatment process, changing the duration of hospital stay and may cause recurrent admissions (7). Studies evaluating the duration of hospital stay in opiate use disorders are quite limited in the literature. Studies on the duration of hospital stay generally evaluated substance addiction under a single heading. The general result obtained from these studies is that the duration of hospital stay is shorter in substance use disorders compared to other psychiatric disorders (8). Some studies also show that the shortened length of stay in psychiatric diseases causes recurrent hospitalizations in patients (9). More research is needed on length of stay and recurrent hospitalizations, which are affected by many variables and remain uncertain.

In this study, we hypothesize that the duration of hospital stays of patients treated in the inpatient ward for opiate addiction will be affected by sociodemographic variables such as age and gender, medical comorbidities, and psychiatric disorders accompanying opiate addiction. However, we suggest that these variables are also effective in the readmission of patients to the inpatient service. The results obtained from the study will make a significant contribution to determining the reasons of longterm hospital stay and readmission to the hospital in a short time in opiate addiction. These results can be a guide for reducing treatment costs by determining the variables that increase the cost in the treatment of opiate, the second most commonly used illicit substance in Turkey. In addition, determination of data on the length of hospital stay in opiate addiction and the reasons for readmission in Turkey will provide the opportunity to compare these findings with the international literature.

\section{METHODS}

This study is a retrospective descriptive study. The study data consisted of patient records of patients treated between January 1, 2005 and December 31, 2017 at Gazi University Hospital Alcohol and Substance Addiction Clinic. Records between 2005-2016 were provided from the hospital database. The records of 2017 were obtained by scanning the patient files from the archive due to the change in the hospital database system. A total of 789 patients with a diagnosis of opiate addiction, 763 between 2005 and 2016, and 26 in 2017, were hospitalized. Daily treatment records and hospitalization records with missing data were not included in the analysis. Among the remaining 621 hospitalization records, it was seen that patients with a single hospitalization $(n=384)$ had one hospitalization record, and patients with recurrent hospitalizations $(n=100)$ had multiple hospitalization records. Only first hospitalization records of patients with recurrent hospitalizations were evaluated. Thus, the impact that multiple data belonging to a patient can have, was limited. As a result, records of a total of 484 patients, 384 with a single hospitalization and 100 with recurrent hospitalizations, were included in the analysis. The operation flowchart is shown in Figure 1.

Patient diagnoses were evaluated by psychiatrists according to Diagnostic and Statistical Manual of Mental Disorders (DSM), fourth edition, text revision and DSM-5. Since the hospital registry system is based on the International Statistical Classification of Disease and Related Health Problems, $10^{\text {th }}$ revision (ICD10) diagnostic classification, psychiatry is registered with the most appropriate ICD-code. Patient records with a diagnosis of "Addiction Syndrome (F11.2) Due to Opioid Use" were included in the study.

In the study, average length of hospital stay was found to be $15.19 \pm 10.89$ days. Since this variable does not show a normal

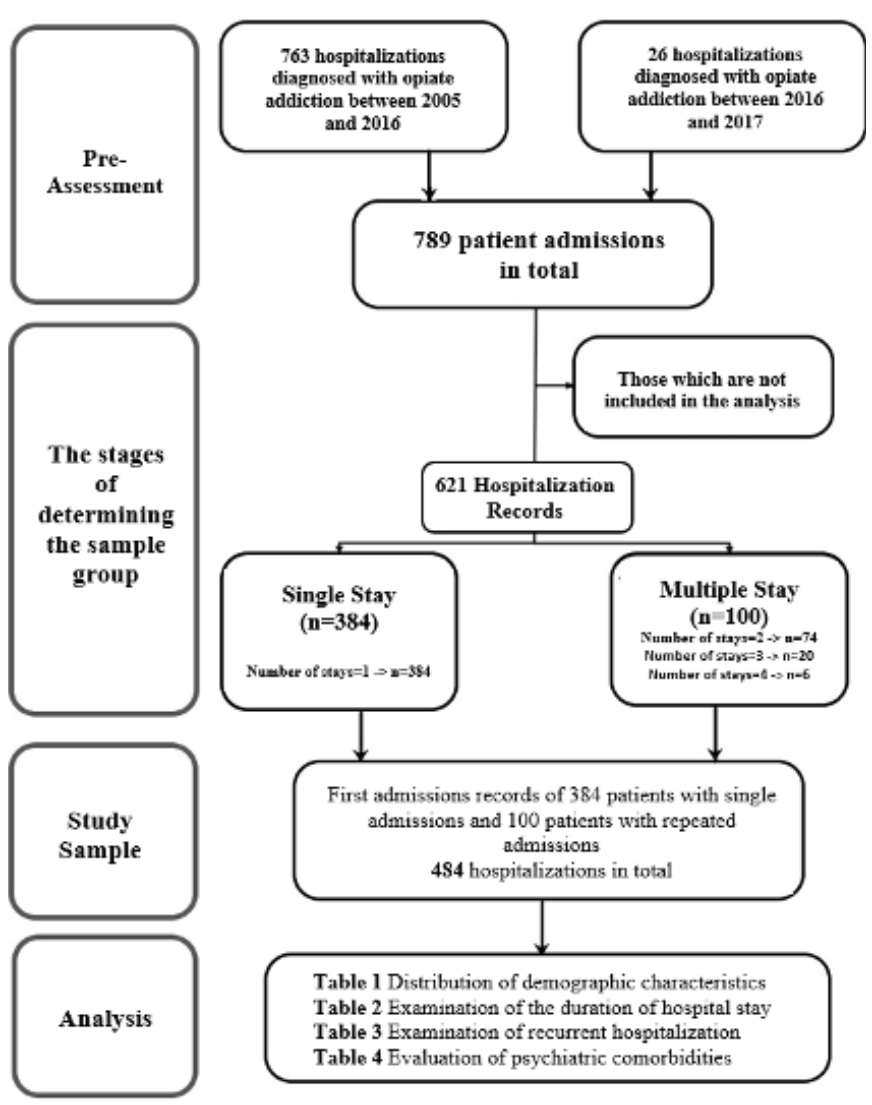

Figure 1. The operation flowchart 
distribution, 14 days, which is the median value of the length of stay in the hospital, was taken as the basis for the distinction between long and short length of stay. Short-term hospitalization was evaluated as 14 days or less, while long-term hospitalization was evaluated as 15 days or more.

Admission records included two hospitalization records of 74 patients, three hospitalization records of 20 patients, and four or more hospitalizations for 6 patients. Patients with two or more hospitalizations ( $n=100)$ were accepted as recurrent admissions. The time elapsed between the first and second hospitalizations of the patients with recurrent hospitalizations was called the "days between the first two hospitalizations".

The time limit for readmission of patients varies between 1-12 months in the relevant literature $(7,10,11)$. It seems that this time period is usually based on a month. In our study, the rate of patients who were readmitted within the first month after discharge was only $5 \%$. In our study, the readmission time was determined as three months in order to examine the variables related to readmission and the statistical limitation caused by the small sample size in this period. In our study, the rate of readmission in the first three months was $29 \%$.

In addition to the diagnosis of opiate addiction, variables such as "There is a psychiatric comorbidity" in the presence of any coded psychiatric disease (e.g., F32-Depressive seizure, F41Anxiety disorders, etc.) for the same patient, and "There is a medical comorbidity" in the presence of a coded physical disease (e.g. R94.5-Liver function tests abnormal results, K86.9-Pancreatic disease, etc.) were created. In addition to the diagnosis of F11.2, a new variable was created as "Psychotic symptom" in those with the diagnosis code "Psychotic disorder due to opioid use (F11.5)". Paranoid personality disorder (F60.0), Emotional inactive personality disorder (F60.3), Histrionic personality disorder (F60.4), Anxious personality disorder (F60.6) and Dependent personality disorder (F60.7) were collected under a single heading due to the low frequency of diagnosis and the presence of "Personality disorders, unspecified (F60.9)" diagnosis.

\section{Statistical Analysis}

SPSS for Windows 23.0 was used for analysis of research data. Mean, standard deviation, median, minimum value, maximum value, frequency and percentages were used for descriptive statistics. Chi-Square test was used for comparing qualitative data and Fisher's Exact test was used when necessary. KolmogorovSmirnov test was used to investigate the compatibility of the data to normal distribution. It was found that the data did not show normal distribution. Spearman correlation test was used to examine the relationship of continuous variables. Logistic regression analysis was used to determine the predictors of length of stay, recurrent hospitalization, and readmission within three months. Short-term hospitalization was evaluated as 14 days and less and was coded as " 0 ". Fifteen days or more was considered as a long-term hospitalization and coded as "1". Similarly, single admission and non-readmission within three months were coded as " 0 ", while recurrent admission and readmission within three months were coded as "1". In the study, the significance value was taken as 0.05 .

\section{Ethical Approval}

This research was discussed at the Gazi University Ethics Committee meeting dated 04.02.2020 and numbered 02, and received ethical approval with the 2020-110 research code. In addition, permission was obtained from the head physician of the hospital that the patient record data would be used. The study design and management was carried out in accordance with the Declaration of Helsinki.

\section{RESULTS}

The demographic data of the sample and some disease characteristics are shown in Table 1. Mean age of the study group was $29.74 \pm 7.05$ (median: 28$)$, while $89.9 \%(n=435)$ were male. Psychotic symptoms were $5.2 \%(n=25)$, medical comorbidity $5.2 \%$

Table 1. Demographic data of the sample and some disease characteristics $(n=484)$

\begin{tabular}{|c|c|c|c|}
\hline \multicolumn{2}{|l|}{ Variables } & Mean (n) & SD (\%) \\
\hline \multirow{6}{*}{ Age } & $\begin{array}{l}\text { Mean } \pm \text { standard } \\
\text { deviation }\end{array}$ & 29.74 & 7.05 \\
\hline & $\begin{array}{l}\text { Median (minimum- } \\
\text { maximum) }\end{array}$ & 28 & $19-61$ \\
\hline & $18-25$ & 140 & 28.9 \\
\hline & $26-35$ & 263 & 54.3 \\
\hline & $36-45$ & 59 & 12.2 \\
\hline & $\geq 46$ & 22 & 4.5 \\
\hline \multirow{2}{*}{ Gender } & Female & 49 & 10.1 \\
\hline & Male & 435 & 89.9 \\
\hline \multirow{2}{*}{ Acceptance status } & Single & 384 & 79.3 \\
\hline & Recurrent & 100 & 20.7 \\
\hline \multirow{2}{*}{ Medical comorbidity } & None & 459 & 94.8 \\
\hline & Exist & 25 & 5.2 \\
\hline \multirow{2}{*}{ Psychiatric comorbidity } & None & 274 & 56.6 \\
\hline & Exist & 210 & 43.4 \\
\hline \multirow{2}{*}{ Psychotic symptom } & None & 459 & 94.8 \\
\hline & Exist & 25 & 5.2 \\
\hline \multirow{4}{*}{$\begin{array}{l}\text { Duration of } \\
\text { hospitalization (days) }\end{array}$} & $\begin{array}{l}\text { Mean } \pm \text { standard } \\
\text { deviation }\end{array}$ & 15.19 & 10.89 \\
\hline & $\begin{array}{l}\text { Median (minimum- } \\
\text { maximum) }\end{array}$ & 14 & $1-60$ \\
\hline & $\leq 14$ & 252 & 52.1 \\
\hline & $>14$ & 232 & 47.9 \\
\hline \multirow{2}{*}{$\begin{array}{l}\text { The days between } \\
\text { the first two } \\
\text { hospitalizations in } \\
\text { patients with recurrent } \\
\text { admissions }(n=100)\end{array}$} & $\begin{array}{l}\text { Mean } \pm \text { standard } \\
\text { deviation }\end{array}$ & 274.22 & 317.10 \\
\hline & $\begin{array}{l}\text { Median (minimum- } \\
\text { maximum) }\end{array}$ & 148 & $5-1539$ \\
\hline SD: standard deviation & & & \\
\hline
\end{tabular}


$(n=25)$, and psychiatric comorbidity $43.4 \%(n=210)$. The mean hospitalization period of the patients was 15.19 \pm 10.89 (median: 14) days. The average readmission period of those with recurrent hospitalizations was $274.22 \pm 317.10$ days. $5 \%$ of the patients $(n=5)$ were readmitted within the first month, 29\% ( $n=29)$ within the first three months, $57 \%(n=57)$ within the first six months and $78 \%$ $(n=78)$ within the first year.

The evaluation of the duration of hospital stay by logistic regression analysis is shown in Table 2. Significant variables predicting the length of hospital stay were found to be age, presence of psychotic symptoms and a diagnosis of depression. It was found that those aged 46 and over stayed in the hospital 3.2 times [odds ratio (OR): 3.204; 95\% confidence interval (Cl): 1.055-9.730] longer than those in the 18-25 age group. In addition to opiate addiction, it was found that comorbid depression prolonged the length of stay 3.3 times (OR: 3.362; 95\% Cl: 1.874-6.032) and having psychotic symptoms 5.4 times (OR: $5.417 ; 95 \% \mathrm{Cl}$ : 1.857-15.798). While the created model was determined significantly, it explained $17 \%$ of the total variance. Evaluation of recurrent hospitalization status by logistic regression analysis is shown in Table 3. Significant variables predicting recurrent hospitalization were found to be age, anxiety disorders, and comorbid personality disorders. Those between the ages of $26-35$ and $36-45$ had 1.88 (OR: 0.531; $95 \% \mathrm{Cl}: 0.303-0.932$ ) and 2.81 (OR: 0.355; 95\% Cl) times lower risk of readmission than those in the 18-25 age group, respectively. A diagnosis of anxiety disorders in addition to opiate addiction increased the risk of readmission by 3.3 times (OR: 3.321; 95\% Cl: 1.690-6.524), while a diagnosis of personality disorder reduced the risk of readmission 4.58 times (OR: 0.218; 95\% Cl: 0.049-0.975). While the created model was determined significantly, it explained $15.9 \%$ of the total variance. An additional model was created in which the independent variable was the length of hospital stay and the dependent variable was readmission within three months $\left(X^{2}=8.210 ; p=0.004\right.$; Nagelkerke $\left.R^{2}=0.113\right)$.

Accordingly, the risk of re-admission within three months was 3.64 times lower $(\mathrm{OR}=0.274 ; 95 \% \mathrm{Cl}: 0.111-0.677)$ in patients with a hospital stay longer than 14 days than those with a hospital stay of 14 days or less.

The relationship between hospital stay and the day of readmission is shown in Figure 2. Accordingly, it was observed that the shortening of the hospitalization period significantly shortened the day of readmission ( $r=0.307 ; p=0.002)$.

The evaluation of psychiatric comorbidities according to age groups and gender is shown in Table 4. A significant difference was found according to age groups in terms of psychiatric comorbidity, anxiety disorders, depression, alcohol dependence, and personality disorder variables $(p=0.007 ; p<0.001 ; p<0.001$; $p=0.002 ; p=0.001$, respectively). However, it was observed that

\section{Table 2. Evaluation of length of hospital stay by logistic regression analysis $(n=484)$}

\begin{tabular}{|c|c|c|c|c|c|}
\hline & & & Len & the hos & \\
\hline Variables & & $\begin{array}{l}\leq 14 \text { days } \\
(n=252)\end{array}$ & $\begin{array}{l}>14 \text { days } \\
(n=232)\end{array}$ & $n$ & OR $(95 \%$ confidence $n$ \\
\hline & & $p$ & $\mathbf{n}$ & & \\
\hline & $18-25$ & 80 & 60 & - & 1.000 \\
\hline & $26-35$ & 138 & 125 & 0.778 & $0.937(0.597-1.471)$ \\
\hline & $36-45$ & 29 & 30 & 0.961 & 0.983 (0.500-1.932) \\
\hline & $46-55$ & 5 & 17 & 0.040 & $3.204(1.055-9.730)$ \\
\hline & Female & 27 & 22 & - & 1.000 \\
\hline 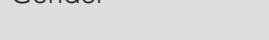 & Male & 225 & 210 & 0.524 & $1.237(0.644-2.377)$ \\
\hline & None & 242 & 224 & - & 1.000 \\
\hline 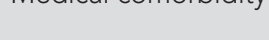 & Exist & 10 & 8 & 0.247 & $0.522(0.173-1.570)$ \\
\hline & None & 247 & 212 & - & 1.000 \\
\hline 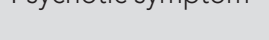 & Exist & 5 & 20 & 0.002 & $5.417(1.857-15.798)$ \\
\hline Ininglar donreccion & None & 216 & 136 & - & 1.000 \\
\hline 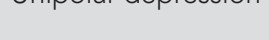 & Exist & 36 & 96 & $<0.001$ & $3.362(1.874-6.032)$ \\
\hline & None & 215 & 149 & - & 1.000 \\
\hline 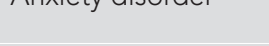 & Exist & 37 & 83 & 0.209 & $1.473(0.805-2.695)$ \\
\hline Porcenality disorder & None & 233 & 215 & - & 1.000 \\
\hline 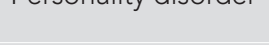 & Exist & 19 & 17 & 0.659 & $1.183(0.560-2.500)$ \\
\hline Alrobol addirtion & None & 245 & 222 & - & 1.000 \\
\hline 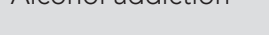 & Exist & 7 & 10 & 0.943 & 1.043 (0.332-3.273) \\
\hline
\end{tabular}




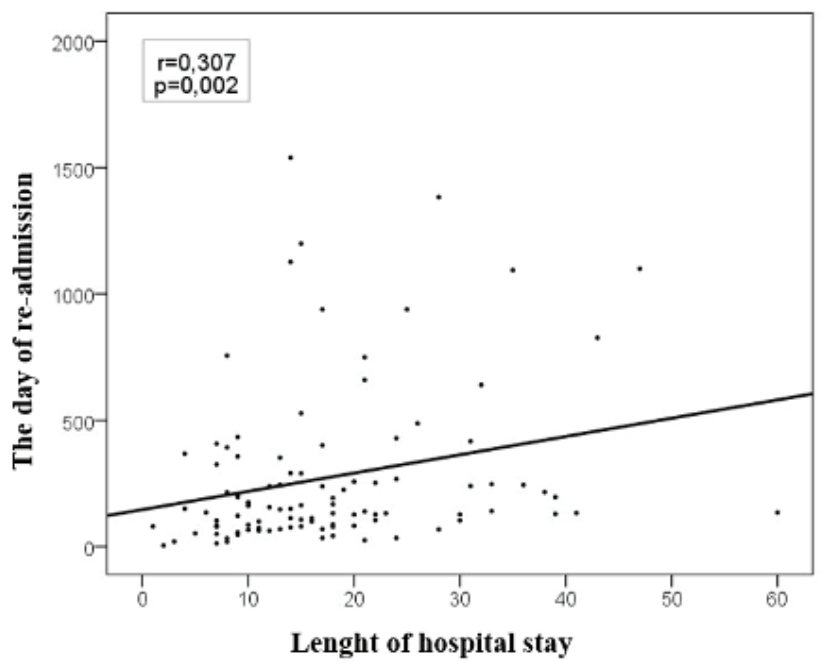

Figure 2. Evaluation of the relationship between the length of hospital stay and the day of re-admission $(n=100)$

there was no significant difference in terms of these variables according to gender (Table 3). It was found that anxiety disorders, depression and alcohol dependence increased with advancing age. Personality disorder was more common in the age group of 35 and under (19.6\% vs. $10.8 \%$ ). With these results, $1.4 \%$ of the whole sample had schizophrenia $(n=7), 1 \%$ had bipolar affective disorder $(n=5), 0.2 \%$ had schizoaffective disorder $(n=1), 0.8 \%$ had cocaine addiction $(n=4), 4.5 \%$ had cannabinoid addiction ( $n=22)$, $1.7 \%$ had sedative, hypnotic or anxiolytic addiction $(n=8), 0.4 \%$ had inhalant addiction $(n=2)$.

\section{DISCUSSION}

In our study, the most important reasons for long-term hospitalization were advanced age, presence of psychotic symptoms, and a diagnosis of depression. Approximately one in three patients was readmitted in the first three months, and one in two patients in the first six months. When psychiatric comorbidities of patients with opiate use disorder were evaluated, $43.4 \%$ of the patients had a psychiatric diagnosis. Depression and anxiety disorders were the most common psychiatric disorders (27.2\% and $24.7 \%$, respectively). While the risk of recurrent hospitalization was 3.3 times higher in those with anxiety disorders, it was 4.5 times lower in those with personality disorders. One of the most important results was that those with a hospital stay of 14 days or less had a 3.6 times greater risk of readmission within three months than those with a long-term (more than 14 days) hospitalization.

The need to control the ever-increasing cost of healthcare is an important issue agreed upon by policy makers all over the world (8). Recurrent admission rate is accepted as important criteria for evaluating the quality of hospital care and discharge planning. Therefore, it has become an important target of health services (10). However, not everything can be explained that easily. Because there are many variables that affect readmission and these variables affect each other in a complex relationship.
Table 3. Evaluation of recurrent hospitalization status by logistic regression analysis $(n=484)$

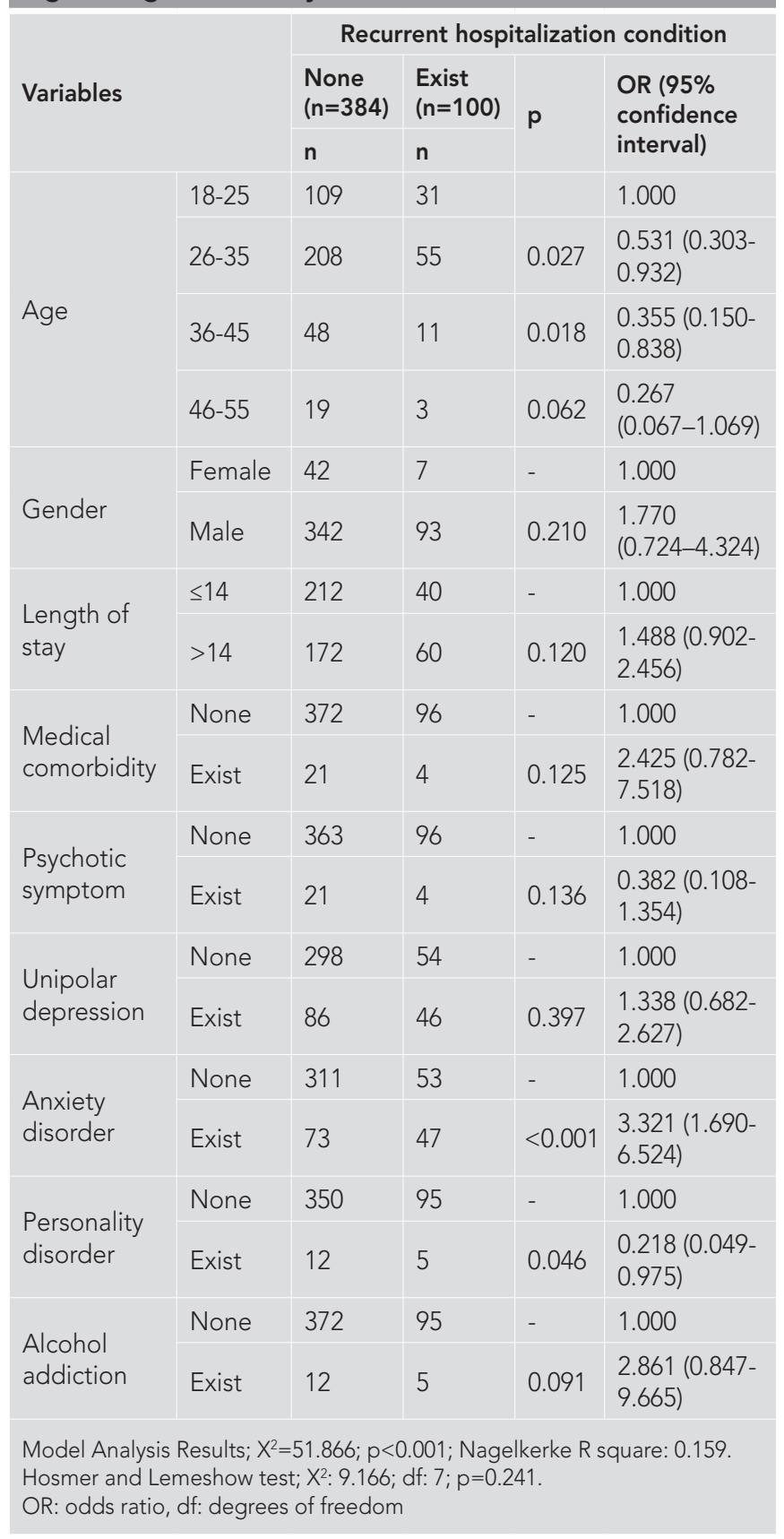

Disease characteristics, health policies, social and environmental factors are the main areas that affect the readmission (11). There are many factors associated with readmission. Some of these are infections caused by the use of opiates by injection, additional non-infectious medical diseases, decrease in pain threshold, presence of additional psychiatric diseases, discontinuation of treatment despite medical advice, severity of addiction and a history of sexual abuse (12). In a study conducted in the United States of America (USA), readmission rate is reported as 19\% within the first month after discharge in patients with opiate addiction (13). In our study, this rate was found to be $5 \%$. The lower rate of readmission in Turkey may be related with the lower 
frequency of opiate addiction compared to the USA. In addition to having recurrent admissions due to opiate use disorders, it has been found to cause readmission by negatively affecting the course of other medical diseases $(7,12,14)$. In inflammatory bowel diseases, the readmission rate is between $18.9 \%$ and $19.4 \%$ while

it is reported as between $28.9 \%$ and $35.1 \%$ in patients with accompanying opiate addiction (14). A similar situation was also observed in patients with pancreatitis. While the readmission rate due to pancreatitis picture was $27 \%$, it was found to be $35.3 \%$ in patients with accompanying opiate addiction (7). In this study, the presence of any psychiatric disease in patients increased the risk of readmission 1.32 times. In our study, it was observed that the presence of anxiety disorders increased the risk of readmission by 3.3 times, while the diagnosis of personality disorder decreased 4.58 times. Depression and alcohol use disorder had no effect on readmission. Here, the result that a diagnosis of personality disorder reduces repetitive acceptances is thought to be quite important. This conclusion may be the effect of stigmatization developed against the patients with substance abuse. A recent study stated that $37 \%$ of Americans see the main cause of addiction in opiate addiction as a weak willpower rather than a medical illness (15). It has been shown that physicians and health policy regulators, who are an important part of the society, also have a similar content of thought $(16,17)$. Negative attitudes and prejudices disrupt communication. Patients' less trust in their physicians, non-compliance with treatment recommendations, and low motivation may distract them from treatment (16). However, the treatment of a patient with personality disorder can be difficult for the physician. As the physician feels helpless and powerless in the face of these difficulties, they may distance themselves from these people. All these may reduce readmission in patients with personality disorders. However, many variables other than these factors may play a role in this process.

Length of hospital stay is another reason for the cost of treatment. Global health policies aim to shorten the length of hospital stay and advocate a community-based rehabilitation process (8).
The length of stay of patients with opiate use disorder may vary depending on many variables, especially the characteristics of the treatment clinic and the method of treatment $(18,19)$. In the study evaluating a large sample in the USA, the mean hospitalization period of the patients was determined as 4.4 days (3.8-5.7). In another study, patients with opiate use disorder and those with non-opiate substance use disorder were compared. It was found that patients with opiate use disorder had an average hospitalization of 32.8 days, while the other group had 30.9 days. In our study, the average length of stay was found to be $15.19 \pm 10.89$ days. The most important factors affecting the length of stay were age of 46 years or older, presence of psychotic symptoms and a diagnosis of depression (Table 2). As the medical and psychiatric comorbidities increase with advancing age, the duration of hospital stay may increase (20). In our study, depression and anxiety disorders were found at a rate of $50 \%$ and $36.4 \%$ in the 46 years and older group, while these rates were found to be $13.6 \%$ and $9.3 \%$, respectively, in the $18-25$ age group. In many studies, it has been shown that a diagnosis of depression in patients with opiate addiction increases the length of stay $(21,22)$. Other variables affecting the length of stay may be differences in the treatment modality applied in the clinic, patient demand and early discharge status $(18,19)$. Studies have reported that patients who are discharged despite medical advice naturally have a shorter hospital stay (23). Patients with incomplete hospitalizations have higher readmission rates compared to other patients $(19,24)$. In a study conducted by Gottheil et al. (9), it has been reported that shortened hospitalizations increase repeated hospitalizations. In our study, the risk of readmission of the patients within three months was found to be 3.64 times lower in those with a hospital stay longer than 14 days compared to those with a shorter hospital stay. In other words, it can be interpreted that the short duration of hospitalization causes a high risk of readmission. In Figure 1 , it is seen that the day of readmission is earlier for those with shorter hospitalization periods. Length of stay and recurrent admission are two variables that closely affect each other. Recurring admission risks should be comprehensively addressed

\section{Table 4. Evaluation of psychiatric comorbidity according to age groups and gender $(n=484)$}

\begin{tabular}{|l|l|l|l|l|l|l|l|}
\hline Variables & & Psychiatric comorbidity & Anxiety disorders & Depression & Alcohol addiction & Personality disorder \\
\hline Age & $\mathbf{n}$ & $\mathbf{n}(\%)$ & $\mathbf{n}(\%)$ & $\mathbf{n}(\%)$ & $\mathbf{n}(\%)$ & $21(15.0)$ \\
\hline $18-25$ & 140 & $47(33.6)$ & $13(9.3)$ & $19(13.6)$ & $2(1.4)$ & $12(4.6)$ \\
\hline $26-35$ & 263 & $117(44.5)$ & $78(29.7)$ & $79(30.0)$ & $6(2.3)$ & $1(1.7)$ \\
\hline $36-45$ & 59 & $35(59.3)$ & $21(35.6)$ & $23(39.0)$ & $6(10.2)$ & $2(9.1)$ \\
\hline 246 & 22 & $11(50.0)$ & $8(36.4)$ & $11(50.0)$ & $3(13.6)$ & 16.097 \\
\hline$X^{2}$ & & 12.112 & 26.624 & 24.073 & 13.868 & 0.001 \\
\hline P & $\mathbf{n}$ & 0.007 & $<0.001$ & $<0.001$ & 0.002 & \\
\hline Gender & 49 & $22(44.9)$ & & & $14(26.8)$ & $3(6.1)$ & $5(10.2)$ \\
\hline Female & 435 & $188(43.2)$ & $12(24.5)$ & $118(27.1)$ & $14(3.2)$ & $31(7.1)$ \\
\hline Male & & 0.051 & $108(24.8)$ & 0.046 & 0.925 & 0.554 \\
\hline$X^{2}$ & & 0.822 & 0.003 & 0.830 & 0.336 & 0.563 \\
\hline P & & & 0.959 & \\
\hline
\end{tabular}


in the goals of healthcare services to shorten the length of stay, and health policies should be planned accordingly.

Substance use disorders are strongly associated with other psychiatric disorders. Although lifelong comorbidity with other psychiatric disorders differ significantly according to studies, rates varying between $44-93 \%$ have been reported (25). Presence of psychiatric comorbidity has been found to be associated with poor prognosis, more psychosocial impairment, high relapse and high mortality rate $(25,26)$. In a study involving a large sample, psychiatric comorbidities were investigated in inpatients and outpatients with opiate use disorder (27). Psychiatric comorbidity rates in hospitalized patients were found to be $7-22 \%$ for alcohol dependence, $15-34 \%$ for anxiety disorders and 19-31\% for depression. However, in outpatients these rates were reported as $2-15 \%, 2-10 \%$ and $2-8 \%$, respectively. In a study evaluating 652 people receiving methadone treatment for opiate use disorder, it was reported that $78 \%$ of the sample had any psychiatric comorbidity, 22\% had major depression, $42 \%$ had anxiety disorders and $12 \%$ had alcohol use disorder (28). In our study, $43.4 \%$ of the sample had any psychiatric comorbidity, $27.2 \%$ depression, $24.7 \%$ anxiety disorders and $3 \%$ alcohol use disorder. Except for alcohol addiction, the results of our study seem to be consistent with these studies. In a study conducted by Evren et al. (29) on 70 people with opiate addiction in Turkey, they reported that $67.1 \%$ had any Axis 1 diagnosis, 52.9\% anxiety disorders, $35.7 \%$ major depression and $5.7 \%$ alcohol dependence. Similar to the result in our study, alcohol dependence was found at a lower rate in this study compared to the studies of western countries. This result may be related to the amount of alcohol use in Turkey. In the report published by the WHO in 2018, it is reported that per capita alcohol consumption in our country is 2 liters (pure alcohol), while this rate is 9.8 liters in Europe (30).

It is very important to state that the study sample belongs to a non-profit university hospital that provides comprehensive and well-equipped services in the field of alcohol and substance addiction treatment. Although the study is single-centered, it was carried out in an institution where patients from many regions, especially the Central Anatolia Region, were followed. This increases the generalizability of the results across the country. It is very important for our study to include a long period of thirteen years and to consider a serious sample. In addition, the use of ICD-10 diagnosis classification as a result of physician interviews rather than patient feedback in forming the study sample is another strength of our study.

\section{Study Limitations}

There are also some limitations in our study due to its long period. Since most of the patient data were accessed from the electronic database, information such as demographic data, social living conditions, doses and patterns of substance use, substance initiation age and treatment modalities were not included in the study. It cannot be denied that part of the sample may be incomplete hospitalization. This can be considered as another limitation of our study. The possibility of patients continuing their treatment in different institutions should not be ignored. This may cause a limitation in the single and repetitive hospitalization variable.

\section{CONCLUSION}

Readmission rates are an important indicator of inpatient care quality. The recurrent nature of addictions, especially opiate use disorder, indicates that there is a greater need for studies evaluating readmission rates in addiction areas. In Turkey, data in these areas are very limited. Our study shows that approximately one out of every three patients is readmitted within the first three months after discharge. While the presence of anxiety disorders increases the recurrent hospitalization 3.3 times, the presence of personality disorder decreases it 4.5 times. In our study, considering that comorbidity of personality disorder is more common in the 18-25 age group, it can be concluded that the presence of personality disorder in early adulthood may prevent access to treatment. The result determined that the presence of personality disorder shorten the length of stay should be definitely considered in further studies. It is one of the expected results that the hospitalization period is prolonged with the variables such as advanced age, psychotic symptoms and depression comorbidity. However, the fact that those with a hospitalization period of less than 14 days are 3.6 times more likely to be readmitted within three months than those with a longer stay indicates that health policies in this area should be reconsidered. Another suggestion is to investigate the effect of health policies in multi-centered, higher sampling and prospective studies in terms of the duration of hospital stay affecting hospital readmission.

Ethics Committee Approval: This research was discussed at the Gazi University Ethics Committee meeting dated 04.02.2020 and numbered 02, and received ethical approval with the 2020-110 research code.

Informed Consent: Retrospective study.

Peer-review: Externally peer-reviewed.

Author Contributions: Surgical and Medical Practices - B.C.; Concept B.G., B.C., Z.A.; Design - B.G., Z.A.; Data Collection and/or Processing - B.G.; Analysis and/or Interpretation - B.G.; Literature Search - B.G., Z.A.; Writing - B.G., B.C., Z.A.

Conflict of Interest: The authors have no conflict of interest to declare.

Financial Disclosure: The authors declared that this study has received no financial support.

\section{REFERENCES}

1. Crowley R, Kirschner N, Dunn AS, Bornstein SS. Health and public policy to facilitate effective prevention and treatment of substance use disorders involving illicit and prescription drugs: an American college of physicians position paper. Ann Intern Med 2017; 166: 733-6.

2. WHO. World drug report 2018. Vienna. United Nations publication: 2018. Sales No. E.18.XI.9.

3. TUBiM. Türkiye uyuşturucu raporu. Ankara. Emniyet Genel Müdürlüğü: 2019. EGM Yayın Katalog No:703.

4. Degenhardt L, Charlson F, Ferrari A, Santomauro D, Erskine H, MantillaHerrara A, et al. The global burden of disease attributable to alcohol and drug use in 195 countries and territories, 1990-2016: a systematic analysis for the Global Burden of Disease Study 2016. Lancet Psychiatry 2018; 5: 987-1012. 
5. Liu JF, Li JX. Drug addiction: a curable mental disorder? Acta Pharmacol Sin 2018; 39: 1823-9.

6. Petry NM, Bickel WK. Therapeutic alliance and psychiatric severity as predictors of completion of treatment for opioid dependence. Psychiatr Serv 1999; 50: 219-27.

7. Charilaou P, Mohapatra S, Joshi T, Devani K, Gadiparthi C, Pitchumoni CS, et al. Opioid use disorder in admissions for acute exacerbations of chronic pancreatitis and 30-day readmission risk: A nationwide matched analysis. Pancreatology 2020; 20: 35-43.

8. Newman L, Harris V, Evans LJ, Beck A. Factors associated with length of stay in psychiatric inpatient services in London, UK. Psychiatr Q 2018; 89: 33-43.

9. Gottheil E, McLellan AT, Druley KA. Length of stay, patient severity and treatment outcome: sample data from the field of alcoholism. J Stud Alcohol 1992; 53: 69-75.

10. Berenson RA, Paulus RA, Kalman NS. Medicare's readmissions-reduction program - a positive alternative. N Engl J Med 2012; 366: 1364-6.

11. Kansagara D, Englander H, Salanitro A, Kagen D, Theobald C, Freeman $\mathrm{M}$, et al. Risk prediction models for hospital readmission: a systematic review. JAMA 2011; 306: 1688-98.

12. Rajbhandari-Thapa J, Zhang D, Padilla HM, Chung SR. Opioid-related hospitalization and its association with chronic diseases: findings from the national inpatient sample, 2011-2015. Prev Chronic Dis 2019; 16: E157.

13. Mejia de Grubb MC, Salemi JL, Gonzalez SJ, Chima CC, Kowalchuk AA, Zoorob RJ. Opioid, cocaine, and amphetamine use disorders are associated with higher30-day inpatient readmission rates in the United States. Subst Abus 2020; 41: 365-74.

14. Charilaou P, Mohapatra S, Joshi T, Devani K, Gadiparthi C, Pitchumoni CS, et al. Opioid use disorder increases 30-Day readmission risk in inflammatory bowel disease hospitalizations: a nationwide matched analysis. J Crohns Colitis 2020; 14: 636-45.

15. POLITICO/Harvard T.H. Chan School of Public Health. Americans' views on policies to address prescription drug prices, the opioid crisis, and other current domestic issues. July 2018.

16. Yang LH, Wong LY, Grivel MM, Hasin DS. Stigma and substance use disorders: an international phenomenon. Curr Opin Psychiatry 2017; 30: 378-88.

17. Avery J, Avery J. The stigma of addiction: An essential guide. New York: Springer Publishing; 2019

18. Amass L, Bickel WK, Higgins ST, Hughes JR. A preliminary investigation of outcome following gradual or rapid buprenorphine detoxification. J Addict Dis 1994; 13: 33-45.
19. Dayal P, Sarkar S, Balhara YPS. Predictors of inpatient treatment completion among females with opioid use disorder: findings from a tertiary care drug dependence treatment centre of India. Indian J Psychol Med 2017; 39: 464-8.

20. Sajatovic M, Bingham CR, Campbell EA, Fletcher DF. Bipolar disorder in older adult inpatients. J Nerv Ment Dis 2005; 193: 417-9.

21. Ding K, Yang J, Cheng G, Schiltz T, Summers KM, Skinstad AH. Hospitalizations and hospital charges for co-occurring substance use and mental disorders. J Subst Abuse Treat 2011; 40: 366-75.

22. Osby U, Tiainen A, Backlund L, Edman G, Adler M, Hällgren J, et al. Psychiatric admissions and hospitalization costs in bipolar disorder in Sweden. J Affect Disord 2009; 115: 315-22.

23. Kenne DR, Boros AP, Fischbein RL. Characteristics of opiate users leaving detoxification treatment against medical advice. J Addict Dis 2010; 29: 383-94.

24. Braune NJ, Schröder J, Gruschka P, Daecke K, Pantel J. Determinants of unplanned discharge from in-patient drug and alcohol detoxification: a retrospective analysis of 239 admissions. Fortschr Neurol Psychiatr 2008; 76: 217-24.

25. Bogdanowicz KM, Stewart R, Broadbent M, Hatch SL, Hotopf M, Strang $J$, et al. Double trouble: Psychiatric comorbidity and opioid addictionall-cause and cause-specific mortality. Drug Alcohol Depend 2015; 148: 85-92.

26. Arendt $M$, Munk-Jørgensen $P$, Sher $L$, Jensen SO. Mortality among individuals with cannabis, cocaine, amphetamine, MDMA, and opioid use disorders: a nationwide follow-up study of Danish substance users in treatment. Drug Alcohol Depend 2011; 114: 134-9.

27. Mallow PJ, Belk KW, Topmiller M, Strassels SA. Geographic variation in hospital costs, payments, and length of stay for opioid-related hospital visits in the USA. J Pain Res 2018; 11: 3079-88.

28. Rosic T, Naji L, Bawor M, Dennis BB, Plater C, Marsh DC, et al. The impact of comorbid psychiatric disorders on methadone maintenance treatment in opioid use disorder: a prospective cohort study. Neuropsychiatr Dis Treat 2017; 13: 1399-408.

29. Evren $E, E r F$, Erkıran M, Çakmak D. Tedavi arayışında olan eroin bağımlılarında I. eksen psikiyatrik komorbidite: sosyodemografik ve madde kullanım özellikleri ile ilişkisi. Klinik Psikiyatri Dergisi 2002; 5: 92104.

30. WHO. Global status report on alcohol and health 2018. Geneva. World Health Organization: 2018. Licence: CC BY-NC-SA 3.0 IGO 